\title{
Knowledge and attitudes of teachers regarding the impact of classroom acoustics on speech perception and learning
}

Lebogang Ramma

University of Cape Town

\begin{abstract}
This study investigated the knowledge and attitude of primary school teachers regarding the impact of poor classroom acoustics on learners' speech perception and learning in class. Classrooms with excessive background noise and reflective surfaces could be a barrier to learning, and it is important that teachers are aware of this. There is currently limited research data about teachers' knowledge regarding the topic of classroom acoustics. Seventy teachers from three Johannesburg primary schools participated in this study. A survey by way of structured self-administered questionnaire was the primary data collection method. The findings of this study showed that most of the participants in this study did not have adequate knowledge of classroom acoustics. Most of the participants were also unaware of the impact that classrooms with poor acoustic environments can have on speech perception and learning. These results are discussed in relation to the practical implication of empowering teachers to manage the acoustic environment of their classrooms, limitations of the study as well as implications for future research.
\end{abstract}

Key Words: Classroom acoustics; Background noise, Reverberation, Teacher's voice,

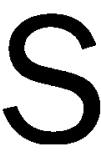
chool classrooms with poor acoustic environment (i.e. excessive background noise levels and too much reverberation) are not suitable for educational activities that requires listening (Anderson, 2004; Crandell \& Smaldino, 2000; Dockrell, Shield \& Rigby, 2004). Excessive background noise in a classroom makes the communication between the teacher and learners difficult because it can cover up part of the verbal mes'sage conveyed by the teachier to learners and vice versa (Crandell \& Smaldino, 1994). Similarily, too many reflective surfaces in the classroom (hence too much reverberation) can cause speech sounds communicated by the teacher to the learners to bounce around the room, leading to blurring of the final speech signal heard by the learners (Guckelberger, 2003). This will make it hard for some learners to hear and understand what is being communicated to them due to poor speech perception. Speech perception in this study refers to the process of hearing and understanding speech signals during normal human communication (Massaro, 2001).

\section{POOR CLASSROOM ACOUSTICS AS A BARRIER TO LEARNING}

Primary school children are more vulnerable to the effects of extraneous noise sources (Shield \& Dockrell, 2004). Therefore, classrooms with too much background noise and reverberation can have a negative impact on learners' speech perception, and consequently their learning (Anderson, 2004). Several studies that investigated the impact of too much background noise in the classroom on learners' ability to learn have shown marked negative effects of noise on learners' reading and numeracy skills, as well as on overall academic performance (Lundquist, Holmberg \& Landstrom, 2000; Mackenzie, 2000; Maxwell \& Evans, 2000; Shield, \& Dockrell, Asker \& Tachmatzidis, 2002). Meaningful irrelevant speech, such as noise from people speaking in an adjacent classroom, has been shown to affect speech understanding, and or learning, to a higher degree than other types of noises (Boman, Enmarker \& Hygge, 2005). Poor acoustics in the classroom have also been shown to have the following effects on learners: high levels of listening fatigue (Hicks \& Tharpe, 2002); poor attentive behaviour, especially when the subject matter is complex or unfamiliar (Anderson, 2004); degradation of the learners' memory capabilities (Boman et al., 2005). Furthermore, apart from being a barrier to the learning process, noise can also be perceived as a nuisance by children. Young children exposed to high levels of noise in their environments report high levels of annoyance with the specific sounds that they are exposed to (Cohen, Evans, Krantz, Stokols \& Kelly, 1981). That is, young children are sensitive to noises in their environment and can Contact: Dr Lebogang Ramma

Division of Communication Sciences and Disorders University of Cape Town Groote Schuur Hospital, F45 Old Main Building Observatory, 7925

Cape Town, South Africa

Email: Lebogang.Ramma@uct.ac.za 
discriminate between those noise sources that annoy them and the ones that do not annoy them (Dockrell \& Shield, 2004; Manlove, Frank \& Vernon-Feagans, 2001).

Classrooms with poor acoustic environments impact negatively on the educational achievement and performance of all learners in the class (Knecht, Nelson \& Whitelaw, 2002), however there are certain categories of children who are at a higher risk for the negative effects of too much background noise in the classroom. These include young children at various stages of language development, learners with home languages different from the language of learning, as well as those with hearing loss (Crandell \& Smaldino, 2000). A study by Broom (2004) revealed that most South African primary school classrooms have learners who are learning in a language that is not necessarily their home language. This means that most South African primary school learners belong to a category of learners who can be considered to be at a higher risk of the negative effects of poor classroom acoustics.

There has not yet been a detailed national study looking at the status of the acoustic environment of classrooms in South African schools. A pilot study conducted in 2006 involving measurement of background noise levels in 15 classrooms from 15 primary schools in the Johannesburg metropolitan area showed that the majority of these classrooms had background noise levels that exceeded both the South African National Standards (SANS) and

Table 1: Background noise levels and reverberation times (RT) measured in 15 Johannesburg primary schools
World Health Organization's (WHO) standards of 35-40 dBA and 0.6 seconds for maximum background noise levels and maximum reverberation times respectively, recommended for an unoccupied classroom (Ramma, 2007).

\section{TYPICAL STRATEGIES FOR ADDRESSING POOR CLASSROOM ACOUSTICS}

The practice in developed countries such as the United States of America for dealing with poor acoustic environments in a classroom involve the use of services of professionals such as acoustical consultants and educational audiologists. Typical interventions include physical modification to the classroom space to enhance its acoustic characteristics, and / or installation of hearing-assistive technology to overcome the problem of noise in the classroom (American Speech-Language Hearing Association (ASHA), 2005). Such intervention measures may not be feasible in a South African context due to the scarcity of skilled personnel such as acoustical consultants and audiologists required to provide these services, and budget constraints to pay for modifications and assistive technology that may be required in these classrooms.

However, one way to address the problem of poor classroom acoustics in South African primary schools could be to work with teachers and to empower them to intervene when their classrooms are not acoustically appropriate. When given the right strategies, teachers responsible for day-to-day management of the classroom environment can play a crucial role in managing background noise levels and amount of reverberation in their

\begin{tabular}{|c|c|c|c|}
\hline Location & Schools & $\begin{array}{l}\text { Unoccupied } \\
\text { background } \\
\text { noise level } \\
\end{array}$ & $\begin{array}{l}\text { Unoccupied } \\
\text { RT60 value } \\
\end{array}$ \\
\hline \multirow[b]{6}{*}{ Suburban } & S1 & 39.9 & 0.87 \\
\hline & $\mathrm{S} 2$ & 40.52 & 0.91 \\
\hline & S3 & 41.85 & 0.86 \\
\hline & S4 & 42.81 & 0.79 \\
\hline & S5 & 45.2 & 0.98 \\
\hline & 56 & 45.54 & 0.59 \\
\hline \multirow[b]{4}{*}{ Township } & S1 & 40.5 & 0.78 \\
\hline & $S 2$ & 41.04 & 0.88 \\
\hline & S3 & 45.08 & 0.81 \\
\hline & $\mathrm{S4}$ & 52.52 & 0.66 \\
\hline \multirow[b]{5}{*}{$\begin{array}{l}\text { School } \\
\text { close to a } \\
\text { noise } \\
\text { source }\end{array}$} & $S 1$ & 40.94 & 0.72 \\
\hline & $\mathrm{S} 2$ & 43.06 & 0.71 \\
\hline & S3 & 48.02 & 0.95 \\
\hline & $S 4$ & 51.81 & 0.72 \\
\hline & S5 & 62.5 & 0.51 \\
\hline
\end{tabular}
that can be shared with teachers include: closing doors or windows (especially those facing noise sources such as traffic noise from busy streets), padding learners' chairs with old tennis balls (De Villiers, 2003) or even removing most of the reflective materials (e.g. mirrors) from the walls to lower the amount of reverberation. Other strategies may involve planning of lessons in a way that takes into account noise levels during the course of the day, with subjects that require more reading being taught during less noisy times than other sub jects (Boman et al., 2005).

36 DIE SUID-AFRIKAANSE TYDSKRIF VIR KOMMUNIKASIE-AFWYKINGS, VOL, 56, 2009 
According to ASHA (2005), the negative effect of classrooms with poor acoustic environments is not self-evident to teachers. Unless this information is brought to their attention, teachers do not usually treat poor classroom acoustics as barriers to learning (ASHA, 2005). The purpose of this study therefore was to explore the knowledge and attitudes of school teachers in selected South African primary schools regarding the impact of too much background noise and reverberation in the classroom on learners' speech perception and learning.

For the purposes of this study, the criteria for adequate knowledge would be met if the respondents indicated that they had some type of input about the subject matter (i.e. impact of poor classroom acoustics on speech perception), and if their responses in the questionnaire showed that they were aware of the impact that too much background noise and reverberation in the class room (i.e. poor classroom acoustics) or poor quality of the teacher's voice would have on speech perception and the learning process That is, a declarative knowledge about these topics at a relational level of understanding when using the SOLO taxonomy (Biggs \& Tang, 2007). According to Biggs and Tang (2007), declarative knowledge refers to "knowing about things, or knowing what," while a relational level of understanding requires one to, among other things, 'relate' things or concepts (p.79). In this study, teachers were required to relate impact of noise to speech perception and learning.

\section{METHOD}

\section{AIM}

To explore the knowledge and attitude of teachers in selected South African primary schools regarding the impact of poor classroom acoustics on learners' speech perception and learning.

\section{OBJECTIVES}

The objectives of this study were therefore as follows:

- To determine teachers knowledge of classroom acoustics (background noise and reverberation) and its impact on speech perception and learning in class.

CTo determine teachers' knowledge about the level of teacher's voice during classroom communication and its impact on speech perception and learning.

ПTo ascertain teachers' opinions and attitudes regarding classroom acoustics, the level of teachers voice and the impact of these factors on speech perception and learning.

To identify strategies used by teachers to enhance speech perception and audibility in class.

To determine whether there is any association between teaching experience or type of qualification and knowledge of classroom acoustics.

\section{RESEARCH DESIGN}

To meet the aims of this study a descriptive cross-sectional survey research design (Bowling, 2009) using quantitative data collection methods was used.

\section{PARTICIPANTS}

To qualify as a participant in the research, subjects had to be currently practising in the teaching profession at primary school level. Therefore, participants included primary school principals, deputy-principals and classroom teachers. School principals and deputy principals at all of the three participating schools were also included as participants in this study because they are also directly involved in day-to-day classroom teaching.

\section{SAMPLING}

Purposive sampling was used to select participating schools. Schools were selected such that one school was from a quiet Johannesburg suburb, the other school was from a major Johannesburg township and the last school was located in a Johannesburg inner-city area (close to most noisy areas). At each school, participants were recruited to participate in this study by way of convenience sampling. All teachers that were present at each of the schools on the day of the survey were invited to participate in this study (and all those who were recruited agreed to participate).

A total of 70 teachers (including principals and deputy principals) volunteered to participate in this study. Fifty-four of the participants were female and sixteen were male. Forty-four had more than 10 years' teaching experience and twenty-six had less than 10 years teaching experience. Twenty-three of the participants had a four year university degree in education or higher while the remaining forty-seven had a diploma in education or equivalent. All of the participants reported using English as the primary medium of instruction in their classes.

\section{DATA COLLECTION PROCEDURE}

Permission was first requested from Gauteng Education Department to conduct the study. This project was also approved by the University of the Witwatersrand Human Research Ethics Committee (non-Medical) (Protocol number H070205). Once permission and ethical clearance were granted, participating schools and participants in this study were selected as described above. School principals were contacted by telephone to request their permission and consent to participate in this study. If they gave permission, an appointment was made at a time convenient for the principal and the entire staff to go and administer the survey questionnaire. At all three schools, the survey was conducted either during the staff lunch break or at the beginning of the weekly staff meeting to avoid disrupting teaching activities.

Each participant was given an information sheet explaining the aims of the study and a consent form to indicate their willingness (or lack of) to take part in the study. After the aim of the study was explained to participants and consent forms were signed, each participant was given the survey questionnaire to complete. The researcher was physically present to answer any questions that arose during the completion of the questionnaire. Questionnaires were collected immediately upon completion, and participants were thanked for their participation. 


\section{DATA COLLECTION TOOL}

A specially constructed questionnaire developed by the researcher was used to gather information for this study. The questionnaire was anonymous and self-administered. It comprised mostly close-ended questions, and contained the following four sections (see Appendix):

Section A: Biographical information;

- Section B: Specific knowledge on classroom acoustics;

Section C: Opinion and attitude of participants regarding classroom acoustics and its impact on classroom learning; and

(] Section D: Strategies used to enhance audibility and speech perception in the classroom.

\section{PILOT STUDY}

The questionnaire was piloted with 10 participants with similar characteristics to the intended study sample to establish reliability and content validity (Maxwell \& Satake, 2006) as well as to obtain representative and unbiased feedback about the questionnaire. The results of pilot testing revealed that teachers were not familiar with most of the technical terms or phrases that are commonly used when discussing room acoustics. The most problematic words or phrases were 'reverberation', 'speech perception' and 'classroom acoustics.' These words (and or phrases) were therefore replaced with more familiar words: reverberation was replaced with too many reflective surfaces in the classroom'; speech perception was replaced with 'hear and understand speech' and classroom acoustics was broken into 'background noise' and 'too many reflective surfaces.'

\section{DATA ANALYSIS}

The results of the questionnaire were analysed using a statistical software package (Statistica-9) to establish patterns of responses between different variables in this study. The statistical test chosen for this purpose was the Pearson Chi-square $\left(X^{2}\right)$ This test is commonly used to compare the observed results with results that are expected based on a certain assumption or according to specific hypotheses (Maxwell \& Satake, 2006). For instance, in this study it was expected that newly qualified teachers (e.g. $<10$ years experience) and teachers with at least a four year university degree in education will be more likely to report knowledge about classroom acoustics than teachers who hold diplomas in education or teachers who have been teaching longer (> 10 years experience).

\section{RESULTS}

This section will present the findings of the study as follows: (1) teachers self-reported knowledge of classroom acoustics; (2) attitude regarding classroom acoustics and the level of teacher's voice in the class and the impact of these factors on speech perception in class; (3) strategies used by teachers to enhance speech perception in class, and (4) association between teaching experience, type of qualification and knowledge of classroom acoustics.

Seventy teachers from three primary schools completed the survey questionnaire for this study. However, eleven of the seventy questionnaires (16\%) had to be discarded because the participants left an entire section of the questionnaire blank. Only fifty-nine (84\%) questionnaires were used in the analysis, therefore the findings reported in the following sections will be based only on responses from these questionnaires $(n=59)$.

\section{1) KNOWLEDGE REGARDING CLASSROOM ACOUSTICS}

Twenty-one (36\%) of the participants reported that their classes were next to a noise source. Traffic was the most frequently cited source of noise, followed by noise from other learners in the playground. Participants were then asked whether they had any formal input on classroom acoustics while they were training to become teachers and / or while working as teachers. Twenty three (39\%) of the participants reported that they had some type of input on classroom acoustics during their training as teachers, and eight (14\%) said they had received some input about classroom noise via in-service training workshops.

Participants were then asked to rate their knowledge regarding the following three factors: too much background noise, too much reverberation in the classroom and level of teacher's voice and furthermore, the impact of these three factors on speech perception (hearing and understanding speech) and learning in the classroom. A five-point Likert scale was used with the following categories: limited, satisfactory, average, good and very good. Most teachers (fifty-one; $86 \%$ ) rated themselves as having average to very good knowledge about the level of the teacher's voice and its impact on learning in the classroom (see Figure 1).

Forty-three (75\%) of the respondents felt they had average or good knowledge about background noise and its impact on

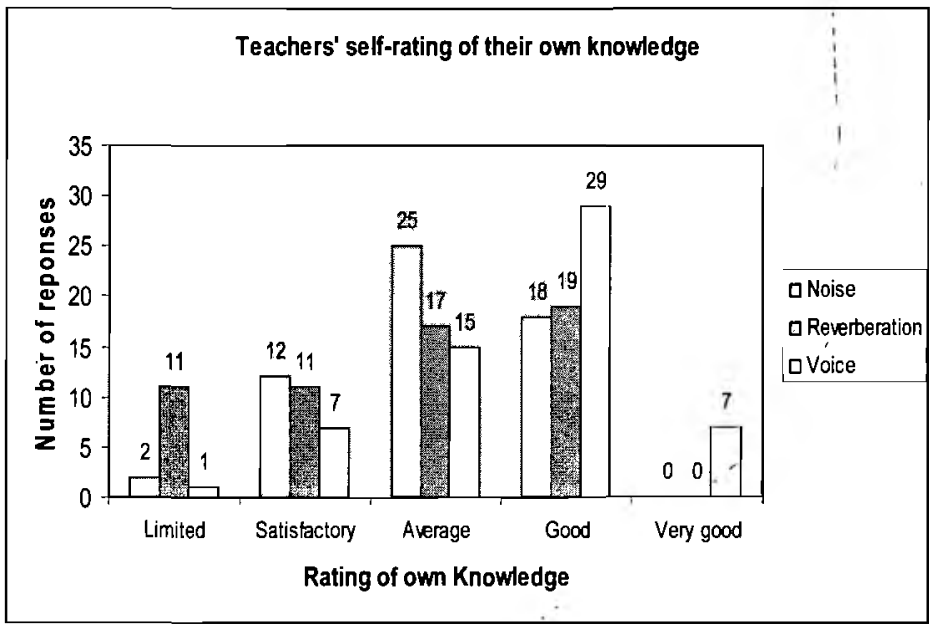

Figure 1: Teachers' self-rating of their own knowledge regarding classroom acoustics 
classroom learning. None of the respondents reported very good knowledge of background noise and its impact on learning. Thirty-six teachers (62\%) rated their knowledge of the impact of having too many reflective surfaces in the classroom on learning as average or good. None of the respondents rated their knowledge here as being very good. Almost all of the respondents (with the exception of four) felt that teachers need some input on classroom acoustics and other factors that influence or affect speech perception in the classroom. Seventeen (31\%) of those who responded felt that this input should be given during teacher training, while sixteen $(29 \%)$ felt that this should be given both during teacher training and as part of in-service training.

\section{2) ATTITUDE REGARDING CLASSROOM ACOUSTICS AND} TEACHER'S VOICE AND ITS IMPACT ON SPEECH PERCEPTION AND LEARNING

Most of the respondents in the survey (thirty-eight; 64\%) were of the opinion that the teacher can play an important role in controlling factors that can impact on speech perception and learning in the classroom (e.g. background noise). Forty-four (75\%) of the teachers who completed the questionnaire reported that they were satisfied with their classroom environment in terms of facilitating adequate speech perception by learners in the classroom. An overwhelming majority (87\%) of the respondents agreed with the statement that if learners' speech perception is compromised due to poor acoustics in the classroom then overall academic achievement will be negatively impacted. However, when respondents were asked to rate the impact that too much background noise, too much reverberation in the classroom, and low level of the teacher's voice may have on speech understanding and learning in the classroom, most were of the opinion that these factors will only have an average (even little or no) impact on classroom learning (Figure 2).

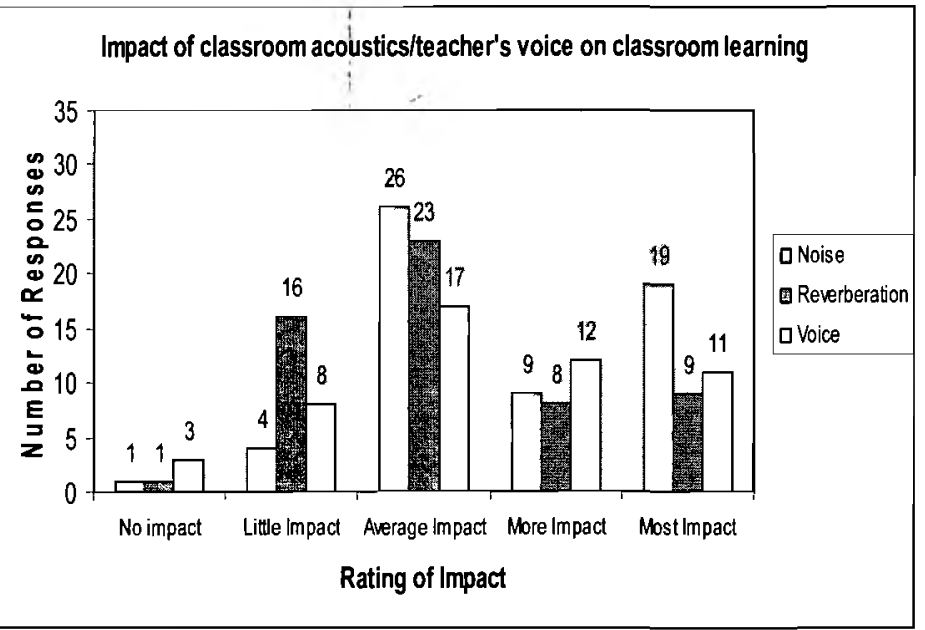

Figure 2: Teachers' views of impact of background noise, reverberation \& level of the teacher's voice on speech perception in the classroom.

\section{3) STRATEGIES USED BY TEACHERS TO ENHANCE SPEECH PERCEPTION AND UNDERSTANDING IN CLASS}

Twenty-eight (47\%) of the respondents reported that they often needed to raise their voices when talking to the learners during normal teaching activities. Only 19 (32\%) reported that they considered the acoustic environment of their classroom when planning or preparing for their daily lessons. The most common strategies used by respondents in this survey to deal with noisy classrooms were; "to speak louder, more clearly and more slowly". Some respondents reported varying their voices according to the noise conditions, while some addressed a noisy classroom environment by organising the learners' seating arrangement in the classroom to favour learners with limited English language communication skills. One respondent reported playing classical music while students did written work as a strategy to help them concentrate better.

\section{4) ASSOCIATION BETWEEN TEACHING EXPERIENCE, TYPE OF QUALIFICATION AND KNOWLEDGE OF CLASSROOM ACOUSTICS}

Tables $1 \mathrm{a}$ and $1 \mathrm{~b}$ show the results of a Pearson chi-square analysis regarding an association between the following variables:

1 -Teaching experience and knowledge of classroom acoustics (Table 2a).

Table 2a: Association between teaching experience and knowledge of classroom acoustics

\begin{tabular}{|l|l|l|l|}
\cline { 2 - 4 } \multicolumn{1}{c|}{} & \multicolumn{2}{c|}{ Knows about classroom } \\
acoustics & Row totals \\
\hline $\begin{array}{l}\text { Experience } \\
\text { No. of yrs } \\
\text { teaching) }\end{array}$ & Yes & No & \\
\hline$<10$ & 9 & 11 & 20 \\
\hline$>10$ & 27 & 12 & 39 \\
\hline $\begin{array}{l}\text { Column } \\
\text { Totals }\end{array}$ & 36 & 23 & 59 \\
\hline $\begin{array}{l}\text { Pearson } \\
\text { Chi-Square }\end{array}$ & $X^{2}=2.150096$, & $d f=1, P=0.14256$ \\
\hline
\end{tabular}


Lebogang Ramma

2 -Type of qualification and knowledge of classroom acoustics

(Table 2b).

Table 2b: Association between type of qualification and knowledge of classroom acoustics

\begin{tabular}{|l|c|c|c|}
\cline { 2 - 4 } \multicolumn{1}{c|}{} & \multicolumn{2}{c|}{$\begin{array}{c}\text { Knowsledge about class- } \\
\text { room acoustics }\end{array}$} & $\begin{array}{c}\text { Row } \\
\text { Totals }\end{array}$ \\
\hline $\begin{array}{l}\text { Type of qualifica- } \\
\text { tion }\end{array}$ & Yes & No & \\
\hline Diploma & 17 & 22 & 39 \\
\hline $\begin{array}{l}4 \text { year degree or } \\
\text { higher }\end{array}$ & 7 & 13 & 20 \\
\hline Column Totals & 24 & 35 & 59 \\
\hline $\begin{array}{l}\text { Pearson Chi- } \\
\text { Square }\end{array}$ & $X^{2}=0.9111253, \mathrm{df}=1, \mathrm{P}=0.33982$ \\
\hline
\end{tabular}

The results of this study showed that there was no association between teaching experience and the probability of being taught about classroom acoustics while training or while working ( $p=$ 0.05). There was also no association between the type of qualification and reporting being taught about classroom acoustics while training or after qualifying as a teacher $(p=0.05)$.

\section{DISCUSSION}

School classrooms are the environments in which most of the learning activities at school occur. The quality of what the learners are expected to learn is therefore partially dependent on the environment in which they learn (i.e. the classroom environment). It is therefore important that the classroom environment should be free of extraneous distractions (e.g. too much background noise) that can interfere with the learning process. Despite the fact that the suitability of learning spaces is planned by architectural designers as early as the design of the school or classroom building (Guckelberger, 2003), teachers are ultimately the people with more control of the daily management of that space. This was a view that was also held by the majority of the participants $(64 \%)$ in this study

It was encouraging to see that some of the participants had received some input on classroom acoustics either during training $(36 \%)$ or after their training as teachers $(12 \%)$. However, overall the results of this study showed that the majority of participants did not have adequate knowledge about the topic of classroom acoustics and the impact that a classroom with a poor acoustic environment could have on the learning process. These findings are consistent with those of other studies, such as the one by Dockrell et al. (2004), in which it was found that despite the fact that noise is a serious problem in urban schools in the United Kingdom, teachers show little awareness of the importance of noise levels in their classrooms and of the need to monitor noise for particular tasks and teaching contexts.

Participants in this study generally rated their knowledge of classroom acoustics and the importance of voice in classroom learning as high (average or better). However, it was evident from responses in later parts of the questionnaire that despite this high self-rated knowledge, most participants did not have adequate knowledge of the impact that a sub-optimal classroom acoustic environment may have on the learners' speech perception in class. For instance, almost half $(44 \%)$ of the participants were of the opinion that excessive background noise in the class will only have an average impact on speech understanding in the classroom while a third (33\%) of the respondents were of the opinion that deterioration in the teacher's voice will have an average impact on speech understanding. One explanation for this observed high self-rating could be the fact that these topics, especially background noise and teacher's voice are generally intuitive phrases to an average teacher. Therefore, teachers may be familiar with the phrase or words because they are part of everyday language in a school setting. However, that does not necessarily mean that they are fully aware of the impact that these factors may have on speech perception and consequently learning in the classroom.

Participants also tended to assume that background noise had a greater negative impact on speech perception and learning than the teacher's voice. This is despite the fact that the negative effect that background noise has in a classroom situation is due to the fact that it covers up part of the teacher's voice and hence degrades the quality of the message communicated to the learners (Crandell \& Smaldino, 1994). The teacher's voice is therefore the most important variable in a classroom situation. Any situation or event in the classroom that compromises the teacher's voice is bound to have the most impact in the learning process. It was therefore expected that participants would rate the impact of the teacher's voice on the learning process higher than any other factors or variable. Surprisingly, a third (33\%) of the teachers who participated in this study were of the opinion that the level of the teacher's voice is less important than too much background in terms of impact on speech perception and learning in the classroom.

Most respondents (75\%) reported that they were satisfied, with the suitability of their classroom environment as a learning environment. This is consistent with the findings of another study (Manlove et al., 2001), in which teachers tended to be more accommodating of noisy classrooms and often dismissed excessive background interference as the "price of doing business." This accommodating attitude is likely to be prevalent if the interfering 
KNOWLEDGE AND ATTITUDES OF TEACHERS REGARDING THE IMPACT OF CLASSROOM ACOUSTICS ON SPEECH PERCEPTION AND LEARNING

noise is from learners on the school property (Manlove et al., 2001) as opposed to noise sources external to the school environment (e.g. traffic noise), even though meaningless, irrelevant speech (noise from an adjacent class or other learners in the playground) has been shown to have the greater effect on interfering with speech perception than other types of noise (Boman, Enmarker \& Hygge, 2005).

Almost half of the respondents said that they often need to raise their voices above their normal talking levels when communicating with learners. This need to raise their voices could be an indication of excessive background noise levels in the classroom. Doyle \& Dye (2003) advised that the best approach to dealing with interfering background noise in the classroom is to be aware of sources of noise (both extraneous and internal) and to start planning teaching activities with this in mind rather than simply talking louder. In the present study only $32 \%$ of respondents said that they considered the acoustic environment of their classroom when planning their lessons. None mentioned any of the common strategies that involve physical modification of the classroom (e.g. carpeting the classroom floors, cushioning the legs of the learners' chairs) as a strategy for enhancing the acoustics.

\section{IMPLICATIONS OF THE STUDY AND FUTURE RESEARCH}

This study showed that the majority of the teachers who took part in this study did not have adequate knowledge about poor classroom acoustics. Teachers therefore need to be given more information on this and also to be trained to recognise the need for an intervention when working in classroom environments that are acoustically inappropriate. Teachers also need to be trained on simple and yet effective, solutions to use when the classroom environment is not conducive to learning due to poor classroom acoustics. This should ideally be addressed in the curriculum during teacher training, as well as in refresher courses for later in-service training for teachers. The results of this study showed that there was no association between teaching experience or the type of qualification that the teacher holds and the likelihood of having received some input on classroom acoustics. This means that refresher courses should target all teachers who are currently working regardless of teaching experiences or the type of qualification they hold.

While this study attempted to investigate key aspects of classroom acoustics (e.g. background noise and reverberation), it was not possible to provide an in-depth investigation of this subject matter due to time and resource constraints. Future studies should aim to explore the feasibility of training current teachers to manage the acoustic environment of the classroom to optimise its use as a space for learning.

\section{LIMITATIONS OF THE STUPDY}

Since information for this study was obtained by using a ques- tionnaire with predominantly close-ended questions, respondents were limited on what they could say because they were not given the opportunity to elaborate on their responses. The questionnaire also contained many terms that were not necessarily familiar to the teachers. While an attempt was made to minimise the number of unfamiliar words during the piloting of the questionnaire, as well as during a briefing before completing it, some of the respondents may have found the questionnaire to be timeconsuming since they were dealing with a subject not necessarily familiar to them. Lastly, this survey was conducted with teachers from only a three schools using non-random sampling and participant selection methods. Although an attempt was made to ensure that the schools selected were heterogeneous and represented diverse geographical areas, it is not possible to generalize the findings of this study to all teachers or schools in the Johannesburg area or to other parts of the country.

\section{CONCLUSION}

The results of this study showed that teachers who participated in this study did not have adequate knowledge about classroom acoustics. Knowledge was especially lacking when it came to indicating how classroom environments with poor acoustics are likely to affect speech perception, and consequently the learning process. Given the linguistic diversity of most classrooms in South African primary schools, it means that most learners who have not mastered the language of learning are likely to be disadvantaged when the classroom environment is not acoustically suitable. This means that teachers need to be given the necessary input to manage the acoustic environment of their classrooms. Different stakeholders, such as teachers, acoustics experts and educational audiologists should come together to address this issue. Management of the acoustic environment of the classroom should ideally also be addressed during teacher training. For teachers who are currently working but do not have adequate knowledge about classroom acoustics and its impact on the learning process, refresher courses could be offered to equip them with strategies to better manage the acoustic environments of their classrooms.

\section{ACKNOWLEDGEMENT}

I thank the Gauteng Provincial Department of Education for granting me the permission to conduct this study.

\section{REFERENCES}

ASHA (2005). Guidelines for Addressing Acoustics in Educational Settings [Guidelines]. Available from www.asha.org/ policy.

Anderson, K. (2004). The Problem of Classroom Acoustics: The Typical Classroom Soundscape is a barrier to learning. Semin Hear, 25, 117-128.

Biggs, J.B. \& Tang, C. (2007). Teaching for quality learning at university. (pp. 72-80). Berkshire, UK: Open University Press. Boman, E., Enmarker, I. \& Hygge, S. (2005). Strength of Noise 
Effects on Memory as a Function of Noise Source and Age. Noise and Health 7 (27): 11-26.

Bowling, A. (2009). Research Methods in Health: Investigating Health and Health Services (pp. 185-235). New York, USA: Open University Press.

Broom, Y. (2004). Reading English in Multilingual South African Primary Schools. International Journal of Bilingual Education \& Bilingualism 7(6): 506-528.

Cohen, S., Evans, G.W., Krantz, D.S., Stokols, D., \& Kelly, S. (1981). Aircraft noise and children: Longitudinal and crosssectional evidence on adaptation to noise and the effectiveness of noise abatement. J Pers Soc/Psychol 40(2): 331-345.

Crandell, C.C. \& Smaldino, J.J. (2000). Room Acoustics for Listeners with Normal hearing and hearing Impairment. In: $M$. Valente, H. Hosford-Dunn \& R. Roeser (Eds). Audiology Treatment. (pp. 601-637) New York: Thieme, .

Crandell, C. \& Smaldino, J. (1994). The Importance of Room Acoustics. In: R. Tyler \& D. Schum (eds.). Assistive Listening Device for the Hearing Impaired. (pp. 142-164) Baltimore, MD: Williams \& Wilkins. .

De Villiers, R. (2003). Factors that influence the reception of spoken language, in sound aspirations : A specialized and informative program for educators who work with learners with hearing loss in mainstream schools. Tygerberg, South Africa. Carel du Toit Centre. Unpublished.

Dockrell, J.E., Shield, B.M. \& Rigby, K (2004). Acoustic Guidelines and Teacher Strategies for Optimising Learning Conditions in Classrooms for Children with Hearing Problems. In: D.A. Fabry, C. DeConde \& Johnson, Z. (Eds), ACCESS: Achieving Clear Communication Employing Sound Solutions-3003. Proceedings of the First International FM Conference. (pp. 217-227) Cambrian Printers Ltd. Great Britain. .

Dockrell, J.E. \& Shield, B. (2004). Children's perceptions of their acoustic environment at school and at home. J Acoustic Soc Am 115(6): 2964-2973.

Doyle, M. \& Dye, L., (2003). Mainstreaming the student who is deaf and hard of hearing. A guide for professionals, teachers and parents. San Diego: Director CCHAT.

Guckelberger, D. (2003). Acoustics in the Classroom. Engineers Newsletter, 32: 1-11.

Hicks, C.B. \& Tharpe, A.M (2002). Listening Effort and Fatigue in School-Age Children with and Without Hearing Loss. Journal of Speech, Language, and Hearing Research, 45(3): 573-584.

Knecht, H.A., Nelson, P. B. \& Whitelaw, G. M. (2002). Background Noise Levels and Reverberation Times in Unoccupied Classrooms: Predictions and measurements. American Journal of Audiology, 11: 65-71.

Lundquist, P., Holmberg, K. \& Landstrom, U. (2000). Annoyance and effects on work from environmental noise at school. Noise and Health, 28: 39-46.

Mackenzie, D. (2000). Noise Sources and levels in UK schools. International Symposium on Noise Control and Acoustics for Educational Buildings. Proceedings, Turkish Acoustical Society, Istanbul, May 2000: 97-106.

Manlove, E.E., Frank, T. \& Vernon-Feagans (2001). Why Should We Care About Noise in Classrooms and Child Care Settings? Child \& Youth Care Forum, 30(1): 55-64.
Massaro, D.W. (2001). Speech Perception. In N.M Smelser \& P.B. Baltes (Eds), International Encyclopedia of Social and Behavioural Sciences (pp. 14870-14875). Amsterdam, The Netherlands : Elsevier.

Maxwell, L. \& Evans, G. (2000). The Effects of Noise on preschool childrens' pre-reading skills. Journal of Environmental Psychology, 20: 91-97.

Maxwell, L.D.\& Satake, E. (2006). Research and Statistical Meth ods in Communication Sciences and Disorders (pp. 279-313). Boston, USA: Thomson/Delmar Learning.

Ramma, L. (2007). Rethinking our classrooms: assessment of background noise levels and reverberation in schools. Education as Change, 11(2): 115-130.

Shield, B. \& Dockrell, J.E. (2004). The Effects of noise on children at school: A review. Building Acoustics 10: 97-116.

Shield, B.M., Dockrell, J.E., Asker, R., \& Tachmatzidis, I. (2002). Effects of Noise on attainments and cognitive performance of primary school children. Report for Department of Health, March 2002. 


\section{Appendix}

\section{Speech Perception Survey Questionnaire}

\section{Directions for completing the questionnaire:}

1. Please use ink pen

2. Please mark with an " $X$ " to indicate your selections

\section{A. Demographic information}

1. Gender

$\square$ Male $\square$ Female

2. Number of years teaching
$\square 0-1$
$\square 2-5$

3. Highest education qualification
$\square$ Dip. Prim. Ed.
B. Prim Ed.
$\square$ BA Ed.
MA. Ed. $\square$ Other:

4. Where did you qualify? Specify training institution:

5. Current post at the school

$\square$ Classroom teacher $\square$ Deputy Principal $\square$ Principal

6. Grade currently teaching (please select one)

$\square 0 \square 1 \square 2 \square 3 \square 4 \square 5 \square 6 \square 7 \square 8 \square 9 \square 10$

7. Grades taught in the past 5 years (select a maximum of 3)

$\square 0 \square 1 \square 2 \square 3 \square 4 \square 5 \square 6 \square 7 \square 8 \square 9 \square 10$

8. Current number of learners in your class

$\square<20 \square 20-25 \square 25-30 \square 30-35 \square 35-40 \square 40-45 \square>45$

9. Primary language used as a Medium of instruction in class (Please select 1)

$\square$ English $\square$ isizulu $\square$ seSotho $\square$ Afrikaans $\square$ isiXhosa $\square$ Other

10. Number of learners in your classroom who speak English as their first/home language (estimate)

11. Is your school/classroom located close to a noise source (e.g. freeway, busy street etc.)?

$\square$ YES $\square$ No

12. If YES above, please specify the nature of noise source: 
13.Does your classroom have the following:
a. Double wall construction
b. Acoustical ceiling tile in hallways
c. Fully carpeted floor
d. Brick wall
e. Posters on the walls
f. Curtains/Blinds in all windows
g. Concrete floors
h. Ceramic Tiles on the floor
i. Ceramic Tiles on the walls
j. Vinyl tiles on the floor

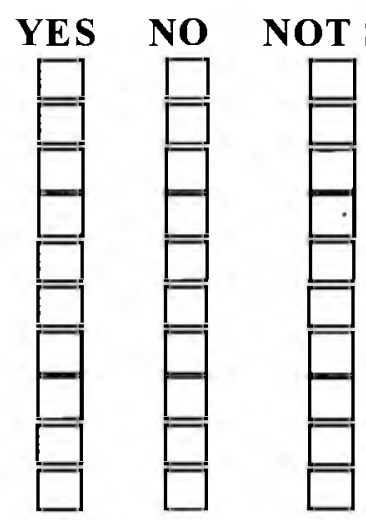

\section{B. Know ledge on Speech perception and classroom acoustics}

1. While you were training as a teacher, did your training curriculum include:

a. Backg round noise and its impact on learning

b. Reflective surface in class and their impact on learning

c. Teaching in a multi-language context

d. Optimizing speech understanding by pupils in the classroom

e. Vocal hygiene and voice projection

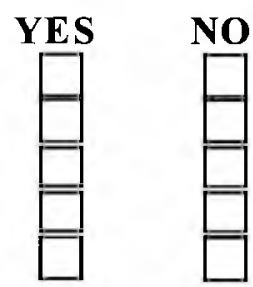

2. Since you started working as a teacher, have you had additional continuing education training on:

a. Background noise and its impact on learning

b. Reflective surfaces in class and their impact on learning

c. Teaching in a multi-language context

d. Optimizing speech understanding by pupils in the classroom

e. Vocal hygiene and voice projection

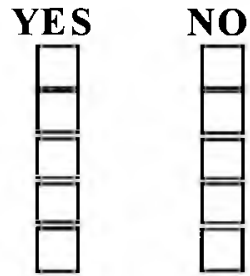

3. Are you aware of any legislation, national education department policy or national standard that deals with any of the following?

a. Learner to teacher ratio in the classroom

YES NO If yes, please specify:

b. Max imu m background noise in the classro om If yes, please specify:

c. Maximum reverberation time in the classroom If yes, please specify:

d. Language of instruction in the classroom If yes, please specify: 
4. How would you rate your knowledge of the following factors and their impact on speech understanding and learning in the classroom:

a. Background noise $\square$ Limited $\square$ Satisfactory $\square$ Average $\square$ Good $\square$ Very Good

b. Reverberant classroom $\square$ Limited $\square$ Satisfactory $\square$ Average $\square$ Good $\square$ Very Good

c. Signal to noise ratio $\square$ Limited $\square$ Satisfactory $\square$ Average $\square$ Good $\square$ Very Good

d. Listening distance $\square$ Limited $\square$ Satisfactory $\square$ Average $\square$ Good $\square$ Very Good

e. Hearing ability of individual learners $\square$ Limited $\square$ Satisfactory $\square$ Average $\square$ Good $\square$ Very Good

f. Linguistic experience of the learners $\square$ Limited $\square$ Satisfactory $\square$ Average $\square$ Good $\square$ Very Good

g. Level of teacher's voice $\square$ Limited $\square$ Satisfactory $\square$ Average $\square$ Good $\square$ Very Good

h. Too many reflective surfaces in the classroom $\square$ Limited $\square$ Satisfactory $\square$ Average $\square$ Good $\square$ Very Good

5. Do you think teachers need specific training on the above mentioned factors that influence/affect speech perception in class?

YES NO

6. If you answered YES in 6 above, when should this training occur?

a. during teacher training in teacher training colleges

b. in service training as continuing education

c. Both (during training and as an in-service training)

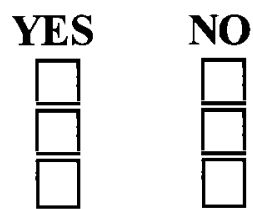




\section{Opinion regarding classroom acoustics and its impact on speech understanding and learning}

1. Are you satisfied with your classroom environment as far as facilitating learners' ability to hear and understand speech?

2. If NO, please explain (use back page if you need more space)

3. In your opinion who has the greatest control on the afore mentioned factors that influence hearing and speech understanding in the classroom? (Please do not select more than 2 choices)

$\square$ Classroom/School designers and planners

$\square$ School administrators (e.g. Principal)

$\square$ Classroom teacher

$\square$ National department of education

4. Rate the following factors on how much impact they will have on speech understanding and learning in the class room?

a. Level of the teacher's noise

$\square$ No Impact $\square$ Little Impact $\square$ Average Impact $\square$ More Impact $\square$ Most Impact

b.Too many reflective surfaces in the classroom

$\square$ No Impact $\square$ Little Impact $\square$ Average Impact $\square$ More Impact $\square$ Most Impact

c. Background in the classroom

$\square$ No Impact $\square$ Little Impact $\square$ Average Impact $\square$ More Impact $\square$ Most Impact

d.Hearing ability of the pupils in classroom

$\square$ No Impact $\square$ Little Impact $\square$ Average Impact $\square$ More Impact $\square$ Most Impact

e. Reverberation in the classroom

$\square$ No Impact $\square$ Little Impact $\square$ Average Impact $\square$ More Impact $\square$ Most Impact

f. Linguistic experience of the learners

$\square$ No Impact $\square$ Little Impact $\square$ Average Impact $\square$ More Impact $\square$ Most Impact

g.Listening distance

$\square$ No Impact $\square$ Little Impact $\square$ Average Impact $\square$ More Impact $\square$ Most Impact 
5. In your opinion, poor hearing and speech understanding in class will lead to:

a. Poor reading/spelling skills

b. Poor mathematics and science skills

c. Behavior problems

d. Attention and concentration problems

e. Poor academic achievement

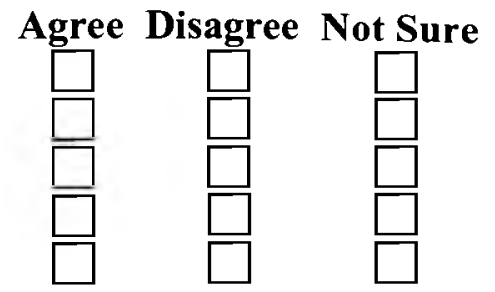

6. In your opinion, what acoustic features in your specific classroom impact negatively on speech understanding? Please list as many as you can:

D.Strategies to enhance hearing and understanding speech as well as audibility in the classroom

1. Do you need to raise your voice when talking to your students during normal teaching activities?

\section{$\square$ YES $\square$ NO}

2. Do you teach with:
a. Door open
b. Windows open
c. Fan on

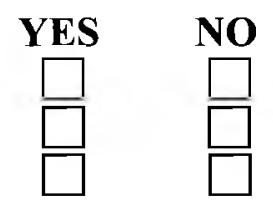

3. Do you consider the acoustic environment of your classroom when you plan and prepare for your lesson? $\square$ YES $\square$ NO

4. Do you have learners with special listening needs (e.g. hearing impairment etc.) in your classroom? $\square$ YES $\square$ NO

5. List some of the things that you do or have done to improve speech understanding in class. List:

6. If you have concerns about the status of your classroom acoustics, what should you do to address that? List:

7. 